\title{
Influence of Higher-Level Skills, Transfer and Culture-Specific Background Knowledge on L2 Reading among Bosnian Students
}

\author{
Jasminka Bavčić ${ }^{1}$ \\ ${ }^{1}$ Department of English Language and Literature, Faculty of Education and Humanities, \\ International Burch University, Bosnia and Herzegovina \\ Email: jasminka.bavcic@stu.ibu.edu.ba
}

DOI: $10.53103 /$ cjlls.v1i3.19

\begin{abstract}
Reading in a second language and how reading in L1 and L2 differ, has been a subject of numerous studies for a long time. Reading in a language other than our mother tongue is not an easy task. Reading in L1 shares many elements of reading in L2, but the processes may differ. Some of the basic questions regarding this matter involve cognitive processes or certain strategies involved in $\mathrm{L} 1$ and $\mathrm{L} 2$ reading. This paper aimed to investigate the influence of higher-level skills, transfer, and culture-specific background knowledge on the L2 reading process. In addition, it also aimed to explore the Bosnian students' opinions on differences in reading Bosnian and English texts.
\end{abstract}

Keywords: Reading, Higher-Level Skills, Background Knowledge, Transfer, L1, L2

\section{Introduction}

Reading is considered a multifaceted, complex language activity because it is practically an innate skill for every person. However, the reading skill must be practised and perfected from childhood onwards. As has been said, it is a complex activity, and we consider that the process of reading is one spiritual, one linguistic, essentially physical, and a communicative sphere. As long as life expectancy lasts, reading after perfection will be an integral part of life like heart rate, respiration, and other primary life functions. When a person enters the sphere of reading books, he becomes "dependent" on new knowledge, new fruits of life, and wanting to reach the peak of all knowledge because reading is like a clear sea, and the sea has no end. Reading requires deep processing and processing in mind, where we sometimes distinguish processing in the sense of learning "under duress" and reading out of love. Usually "by compulsion" we mean learning the required literature in schools and colleges, and by reading "out of love for knowledge", we mean a fast process of processing, because the body and brain function according to persons' intention, desire and will.

Reading is seen as an essential skill among other skills in EFL (Anderson, 2003). 
Despite often being seen as a passive process, reading is not always as it seems to be. When we read, we are involved in several ways. According to Carter and Long (1991, p.16), when we read, we interpret what the text means, we connect the experience of the text with our own experience, and we try to fit into the world the writer has created. According to Clarke (1979), reading is an active process in which the reader samples linguistic cues and produces hypotheses about the author's message. Reading is also an interactive process that includes cognitive abilities such as predicting and guessing. In order to read effectively, students are supposed to read extensive information from books, research articles and many other sources. It is a process that involves the reader, the text, and the interaction between these two (Rumelhart, 1977).

To examine the influence of $\mathrm{L} 1$ reading on $\mathrm{L} 2$ reading, it is important to understand the nature and the processes of both L1 and L2 reading. Reading in L1 shares many elements of reading in $\mathrm{L} 2$, but the process also differs. In both $\mathrm{L} 1$ and $\mathrm{L} 2$, reading requires knowledge of content, form, and linguistic schema (Singhal, 1998). Readers often use mental activities to construct the meaning of the text. L1 and L2 readers engage in these activities (known as reading strategies or reading skills) to enhance text comprehension. These multiple cognitive processes are related to each other, and they involve recognising letters, characters, and words, analysing the syntactic and semantic structure, and generating inferences (Horiba, 1996).

To better understand the processes involving reading comprehension, it is explained by the performance on tasks that measure components of the reading comprehension process. According to Chun \& Plass (1997, p.61), there are two components of reading comprehension: lower-order (letter identification, word recognition and syntactic parsing), and higher-order (applying knowledge about the text and genre characteristics and using reading strategies). Reading comprehension (understanding of a text) is a process that is affected by a variety of factors such as background knowledge, interest in the text, comprehension of the printed characters, the mastering of reading strategies (such as inferencing and predicting) and linguistic ability (Barnett, 1989, p.343).

L2 learners use L1 knowledge and different strategies to facilitate their learning of L2. This phenomenon is known as a transfer. The transfer occurs consciously as a communication strategy when there is a gap in the learner's knowledge and unconsciously when the correct form is not known or has not been automatised (Benson, 2002).

Even though numerous studies have investigated the influence of L1 to L2 reading, a few have conducted specific research regarding factors such as higher-level skills, transfer, and culture-specific background knowledge in the Bosnian EFL reading context.

Thus, this paper aims to investigate higher-level skills, the role of transfer and culture-specific background knowledge as factors that influence L2 reading. Moreover, it is going to conduct qualitative research that aims to investigate whether students read texts in English and Bosnian language in a different way. 


\section{Review of Related Literature}

\section{Higher-level Skills}

Higher-level skills include inferencing, comprehension monitoring, and awareness of text structure. These three skills are crucial for understanding stories, complex directions, conversations, and informational texts (Hogan, Bridges, Justice, \& Cain, 2011).

Schoonen, Hulstijn \& Bosser (1998) conducted research on Dutch learners learning English. They concluded that as proficiency grew, metacognitive knowledge had a stronger influence on L2 reading comprehension skills. It is stated that "knowledge of text characteristics, reading strategies, and knowledge of reading goals are important domains" (p. 98). Concerning this matter, Grabe \& Stoller (2002:148) state that metacognitive instruction about text structure and reading structure should support more advanced reading.

According to Anderson (1991, 1999), readers have different approaches to strategies and those who use more strategies comprehend better. Less skilled readers are less able to choose the appropriate strategy. Furthermore, L2 learners who are L1 good readers use many same strategies used by successful native readers when reading L2 texts (Drucker, 2003). According to Hardin (2001), strategic behaviours in L1 affect L2 reading behaviours, and L2 proficiency level has impact on L2 strategic reading less than the level of using strategies in L1. Similarly, Maeng (2005) concluded that participants of his study used different L1 and L2 reading strategies depending on the reading stage.

As for the role of teachers, Anderson (1991) suggested reading strategies students should be taught in class to improve reading comprehension. In this way, they can help learners become aware of the strategies they use or what other strategies are available and how to use these strategies in certain situations. On this basis, Kucan \& Beck (1997) helped L1 readers work with the texts that were too difficult by giving them the means for critically understanding the text and the author's purpose.

In line with the research mentioned above, teachers should implement higher-level skills in the classroom. One way of teaching inferencing is a "think-aloud" technique in which teachers go through the text demonstrating the dialogue between the reader and the text. Students can also do the same demonstrations in groups or pairs (Brown et al., 1996). Moreover, it is suggested that by implementing the think-aloud technique, inference skills can be developed through predicting future events, focusing on the intentions and feelings of the character, and filling in the gaps. (Hogan, Bridges, Justice, \& Cain, 2011). Comprehension monitoring is a strategy that sometimes needs continual practice to use while reading. It can be taught by instructions that include summarising essential points, teacher modelling and giving corrective feedback (Hogan, Bridges, Justice, \& Cain, 2011). Another step is teaching students how to comprehend text structure for narrative and 
expository texts (Gersten, Fuchs, Williams, \& Baker, 2001). Moreover, according to Hogan, Bridges, Justice and Cain (2011), understanding a text plays a crucial role in reading comprehension.

\section{Language Threshold Hypotheses and Role of Transfer}

In many academic settings, students begin to read in L2 only after learning literacy skills and content knowledge in L1. As a result, they know which reading strategies to use to comprehend the text and become strategic readers. It is believed that not all $\mathrm{L} 1$ reading strategies transfer to $\mathrm{L} 2$ reading context; it is much easier to raise awareness and practice strategies that have been productive in L1 (Grabe \& Stoller, 2011).

L2 proficiency plays an essential role as a basis for L2 reading (the theory known as The Language Threshold Hypothesis). According to the Language Threshold Hypothesis, students must have sufficient L2 knowledge (vocabulary, grammar and discourse) to use skills and strategies as part of their L1 reading comprehension abilities (Clarke, 1980). Readers cross the threshold when they encounter L2 texts in which they are familiar with almost all words and can fluently process the text. The threshold varies on the reader, the text difficulty, the topic, and the task (Grabe \& Stoller, 2011). According to Alderson (2000), L2 knowledge is more important than L1 reading abilities, and the linguistic thresholds must be crossed before the L1 reading ability can transfer to the L2 reading context. However, it indicates that the linguistic threshold is not absolute but varies by task; the more demanding the task, the higher the threshold.

An extension of the Language Threshold Hypothesis is the issue of transfer. The transfer is a phenomenon that occurs when L2 learner uses various strategies and knowledge from L1 to facilitate learning of L2. This is in line with Chomsky's (1979) universal grammar theory, according to which by producing a new language, they transfer their own grammar to any other language (Lakshmanan, 1994). According to Grabe \& Stoller (2011), the transfer is assumed to influence beginning and intermediate levels of L2. When L2 students are supposed to read the material that is difficult for them, they rely on available resources to make sense of the text. At beginning L2 levels, the resources are their L1 abilities, L1 reading abilities and their world knowledge. Sometimes these resources provide enough space for carrying out certain tasks, but sometimes they slow down the L2 process routine. They also found that at lower levels, the training goals for students are to develop vocabulary, practise reading and processing fluency in L2 so that they rely less on $\mathrm{L} 1$. One of the ways to move beyond $\mathrm{L} 1$ interference on $\mathrm{L} 2$ reading is to make sure that students do not read the texts that might be too difficult; the text should be easy and enjoyable to read. Students also transfer their previous experience to tasks such as academic tasks that involve L2 reading texts. However, the transfer is often seen as problematic because it is difficult to transfer immediately to new contexts and situations. 
One of the ways to employ positive effects of transfer is to explore what L1 strategies might positively affect L2 reading development and to reinforce them through the instruction of, for example, vocabulary-learning strategies, comprehension strategies and word recognition strategies.

Much research has been conducted to understand the role of transfer as well as the relationship between L1 and L2 in terms of vocabulary and comprehension skills.

Lambert \& Tucker (1972) investigated English speaking students in French schools and concluded that the students who had received reading instructions in French performed at the same level as the average students that received instructions in EnglishOn-English word knowledge. Based on this, they concluded that the students had used the skills they had developed in French for performing reading tasks in English.

Similarly, some studies attempted to find the relationships between knowledge of vocabulary and reading in English (Fitzgerald, 1995). The findings revealed that English vocabulary if an essential determinant of reading comprehension for English as L2 readers, and that students whose first language has many cognates with English have advantages in recognising English vocabulary (August, Calderon, \& Carlo, 2000).

Furthermore, to understand transfer in L2, some studies have investigated the concept of transfer of comprehension skills. Cummins et al. (1984) investigated the Japanese and English reading skills of Japanese students. The results revealed strong relations between the performance of Japanese proficiency and the performance of English proficiency. The conclusion was that children who arrived in Canada at an older age and with a better command of their native language had better academic achievement in English.

Some other studies reported that comprehension strategies are transferred to L2. Escamilla (1987) investigated native language reading achievement and L2 oral proficiency as predictors of L2 reading achievement. The results revealed that Spanish reading comprehension skill best predicted scores on the English vocabulary test and the English comprehension test.

According to August, Calderon and Carlo (2000), strategies such as prediction, summarizing and questioning has been efficient for poor L1 learners, and evidence suggests it would be useful for L2 learners. Jimenez (1996) revealed that successful bilingual students use certain strategies for comprehending Spanish and English texts. These strategies were: using cognates as a source, focusing on unknown words, monitoring comprehension, actively using prior knowledge, and making inferences.

\section{Culture-Specific Background Knowledge}

Background knowledge has an important influence on L2 reading (Barnett, 1989). Most research related to the influence of background knowledge was based on Carrell's 
paradigm (1987). In a study that involved high-intermediate Muslim Arab and Catholic Hispanic students, two texts were presented. Students read both texts, with Muslim content and Catholic content. After reading each text, students were asked to answer several multiple-choice questions and to recall the text. The results suggested that the participants better comprehended the parts of the text that were similar or related to their own culture or that were more familiar to them. Many similar studies (e.g., Johnson, 1981) suggested that participants comprehended better texts that were more familiar to them. Steffenssen et al. (1979) conducted research by giving texts about weddings to Indian and South American L1 readers and observed how cultural familiarity led the readers to make inferences about the situation in the texts. Further studies confirmed that giving L2 readers information about the culture helps them with reading comprehension.

Moreover, Johnson (1982) compared students' recall reading passages about Halloween. The passage included familiar and unfamiliar information based on their previous experience regarding the customs related to Halloween. Students were supposed to study the meaning of the unfamiliar words. Results suggested that previous background cultural knowledge prepared readers for comprehension of familiar information from the text. On the other hand, unknown words did not have a significant effect on reading comprehension.

Similarly, Kang (1992) conducted a similar study in which he investigated how L2 readers filter information from L2 texts through culture-specific background knowledge. Korean students with advanced English were obliged to read stories and provide answers. Think-aloud protocols indicated an effect of culture-specific inferences upon comprehension of the text. Even though many factors related to how culture shapes background knowledge and affects reading are not entirely understood, there is a concession that background knowledge plays a vital role in reading comprehension in L1 and L2. Given this, readers have a higher level of comprehension when the text content is familiar to them.

\section{Methodology and Participants}

This study aimed to investigate the influence of higher-level skills, transfer, and culture-specific background knowledge on the L2 reading process. In addition, it also aimed to explore the Bosnian students' opinions on differences in reading Bosnian and English texts.

The research was conducted on 7th-grade primary school students from Sarajevo, Bosnia and Herzegovina. A total number of students who participated in the study was 20, and it was voluntarily. Students were supposed to provide an answer to the question: "Do you read differently when reading Bosnian and English texts?" It was designed to get students' opinions on the subject matter. A qualitative method was used to describe and compare their answers. 


\section{Qualitative Investigation of the Influence of Higher-Level Reading Skills, Transfer and Culture-Specific Background Knowledge on L2 Reading}

RQ: Do you read differently when reading Bosnian and English texts?

In order to answer the research question, students were asked to read the question carefully, ask for further explanation if there is something they do not understand and give their own opinion and experience.

The qualitative analysis revealed that the majority of the students enjoy reading the texts both in their L1 (Bosnian) and L2 (English) only if they are familiar with the content of the text, the vocabulary, and if it is related to the topic they are interested in. This is in line with Barnett's (1989) explanation of reading comprehension. One of the possible reasons for this view is that students are probably more comfortable with both L1 and L2 texts they can relate to. One of the answers that provide an insight into these opinions is listed below:

"I personally think that there is no difference in reading in Bosnian and English if I know the vocabulary and if the topic is interesting to me. I always enjoy reading the texts that are related to sports or science."

"Reading in English and Bosnian is pretty much the same. It all depends on text difficulty, the topic and how the text is structured. Reading in English can even be more interesting because many texts are more available in English than in Bosnian."

The answers also suggested that students are more likely to engage in predicting what the text might be about in English than in Bosnian. They also preferred certain exercises that are employed during reading, such as "filling in the gaps", summarizing main points, guessing the meaning of the unknown words and using prior knowledge. The answers are in line with previous studies conducted by Hogan, Bridges Justice, and Cain (2011), and August, Calderon, and Carlo (2000).

"I like to think about what the text will be about when I read the title. I also like when teachers ask questions before we read the text. It makes me happy to participate and express my opinion about the topic."

"For me, the main difference between reading texts in Bosnian and English is that in English we have to make guesses about the meaning of the unknown words, filling in the gaps. I like when the teacher gives us clues, and we have to guess if we are right or wrong. I also like to use knowledge of Bosnian language when I read in English.”

An interesting observation is the role of teachers in the reading process that 
students mentioned. This is one more proof that students view teachers are the facilitators of the reading process, and they should be able to identify which strategies work best for their students. In this case, it can be argued that students are pretty much satisfied with the strategies that teachers employ. This is in line with the research made by Anderson $(1991,1999)$. Furthermore, the student mentioned using previous knowledge of L1 (Bosnian) to reading in L2 (English) being helpful. Thus, it can be seen how students are aware of the influence of transfer on L2. A similar observation was made by Jimenez (1996).

Another observation is related to the influence of the Language Threshold Hypothesis and culture-specific background knowledge.

"Reading in Bosnian is easier, of course. It is my native language; I use it every day in my life. Sometimes I do not understand the meaning of the words in the English texts, and I am afraid to ask my teacher, so I use a dictionary. When we read the texts in English about other people or countries, I understand it better when the teacher gives us some additional information about their culture before we start reading."

"I feel I am confident to read in English when I understand enough the vocabulary and grammar. Otherwise, I prefer reading in Bosnian."

As we can see, these answers suggest that culture-specific background knowledge has an essential role in reading comprehension of L2. This is in line with the similar studies of (Johnson et al., 1981). Knowledge of the subject matter generates interest and motivates students for reading. Moreover, it is evident that students still have problems regarding reading in L2. They do not engage in reading the English texts they are not familiar with since it requires communication and asking teachers for further explanation. In addition, it also suggests that gaining a sufficient amount of L2 proficiency (vocabulary and grammar) stimulates their confidence and desire for $\mathrm{L} 2$ reading. This can be linked to the Language Threshold Hypothesis (Clarke, 1980).

\section{Concluding Observations}

Reading as a skill is crucial for communication flow, everyday life, and academic achievement. It is a complex activity that involves the reader, the material, and the interaction between these two. The review of previous literature, and qualitative research suggests that there is a correlation between reading in L1 and L2. To construct the meaning of the text, students often engage in certain activities that are called reading skills or reading strategies. For better understanding of the processes regarding reading comprehension, there are two components: lower-order and higher-order components. Reading comprehension is a process that is affected by various factors such as background 
knowledge, interest in the text, comprehension of the printed characters, the mastering of reading strategies (such as inferencing and predicting) and linguistic ability. Higher-level skills such as inferencing, comprehension monitoring and awareness of text structure have an important influence on L2 reading. Based on previous research studies and the data derived from qualitative analysis, teachers have an important role in teaching certain strategies in text comprehension, raising awareness and importance of reading in L2 and motivating students. By training and implementing these strategies as well as observing students' strategic behaviours, teachers can improve the overall process of reading in L2. They should be able to recognise what each student needs and what strategies work best for each student. Culture-specific background knowledge also plays an important role in L2 reading. Based on numerous studies, it was concluded that students who had previous background cultural knowledge comprehend better. Moreover, it was confirmed that giving L2 readers information about the culture helps them with reading comprehension. This article shed some light on how higher-level skills, transfer, and culture-specific background knowledge affect L2 reading. It also investigated the attitudes of Bosnian students regarding differences in reading of Bosnian and English texts. An overall study suggested that students know how to use certain strategies to comprehend better. It also revealed that even though the students are highly aware of the importance of higher-level skills and their role in L2 reading, they still lack confidence concerning communication with their

teachers. Thus, the recommendation for further investigation regarding this matter is related to the analysis of teacher's opinions on students' reading differences in Bosnian and English language.

\section{References}

Alderson, C. (2000). Assessing reading. New York: Cambridge University Press.

Anderson, N. (1991). Individual differences in strategy use in second language reading and testing. Modern Language Journal, 75, 460-472.

Anderson, N. (1999). Exploring second language reading: Issues and strategies. Heinle \& Heinle.

Anderson, N. J. (2003). Scrolling, clicking, and reading English: Online reading strategies in a second/foreign language. The Reading Matrix, 3(3), 1-33.

August, D., Calderon, M., \& Carlo, M. (2000). Transfer of skills from Spanish to English: A study of young learners. ERIC Document (ED-98-CO-0071).

Barnett, M.A. (1989). More than meets the eye: Foreign language reading theory and Practice. Englewood Cliffs, NJ: CAL \& Prentice Hall.

Benson, C. (2002). Transfer/Cross-linguistic influence. Elt Journal, 56 (1), 68-70.

Brown, R., Pressley, M., Van Meter, P., \& Schuder, T. (1996). A quasi-experimental validation of transactional strategy instruction with low-achieving second-grade students. Journal of Educational Psychology, 88,18-37.

Carrell, P.L. (1987). Content and formal schemata in ESL reading. TESOL Quarterly, 
21, 461-481.

Carter, R., \& Long M.N. (1991). Teaching literature. New York: Longman Inc. Chomsky, N. (1979). Language and responsibility. New York: 81. Martin's Press.

Chun, D. M., \& Plass, J. L. (1997). Research on Text Comprehension n Multimedia Environments. Language Learning \& Technology, 1(1), 60-81.

Clarke, M. (1980). The short circuit hypothesis of ESL reading: Or when language competence interferes with reading performance. Modern Language Journal, 64, 203-209.

Clarke, M. A. (1979). Reading in Spanish and English: Evidence from adult ESL students. Language Learning, 29 (I), 121-143.

Cummins, J., Swain, M., Nakajima, K., Handscombe, J., Green, D., \& Tran, C. (1984). Linguistic interdependence among Japanese and Vietnamese immigrant students. In C. Rivera (Ed.), Communicative competence approaches to language proficiency assessment: Research and application. Clevedon, Avon, UK: Multilingual Matters LTD.

Drucker, M. J. (2003). What reading teachers should know about ESL learners. The Reading Teacher, 57(1), 22-29.

Escamilla, K. (1987). The relationship of native language reading achievement and oral English proficiency to future achievement in reading English as a second language. Unpublished doctoral dissertation, University of California, Los Angeles.

Fitzgerald, J. (1995). English-as-second-language reading instruction in the United States: A research review. Journal of Reading Behaviour, 27, 115-152.

Gersten, R., Fuchs, L. S., Williams, J. P., \& Baker, S. (2001). Teaching reading comprehension strategies to students with learning disabilities: A review of research. Review of Educational Research, 71, 279-320.

Grabe, W. \& F. L. Stoller (2002, 2011). Teaching and researching reading. Harlow: Pearson Education Ltd.

Hardin, V. B. (2001). Transfer and variation in cognitive reading strategies of Latino fourth-grade students in a late-exit bilingual program. Bilingual Research Journal, 25(4), 417-439.

Hogan, T., Bridges, M. S., Justice, L., M., \& Cain K. (2011). Increasing higher level language skills to improve reading comprehension. Focus on Exceptional Children, 44 (3), 1-20.

Horiba, Y. (1996). Comprehension processes in L2 reading: Language competence, textual Coherence, and inferences. Studies in Second Language Acquisition, 18, 433-473.

Jimenez, R.T., Garcia, G. E., \& Pearson, P. D. (1996). The reading strategies of bilingual Latino students who are successful English readers: Opportunities and obstacles. Reading Research Quarterly, 31, 90-112.

Johnson, P. (1981). Effects on reading comprehension of language complexity and cultural background of a text. TESOL Quarterly, 15(2), 169-181.

Johnson, P. (1982). Effects on reading comprehension of building background knowledge. TESOL Quarterly, 16(4), 503-516.

Kang, H. (1992). The effects of culture-specific knowledge upon ESL reading 
comprehension. School of Education Review, 4, 93-105.

Kucan, L. \& I. Beck (1997). Thinking aloud and reading comprehension research: inquiry, instruction, and social interaction. Review of Educational Research, 67,271-99.

Lakshmanan, U. (1994). Universal grammar in child second language acquisition. Amsterdam: John Benjamin Publishing Co.

Lambert, W.E., \& Tucker, G.R. (1972). Bilingual education of children. The St. Lambert Experiment. Rowley, MA: Newbury House.

Maeng, U. K. (2005). A comparative study of reading strategies in L1 and L2: Case study of five Korean graduate students. Language Research, 41(2), 458-486.

Rumelhart, D. E. (1977). Toward an interactive model of reading. In S. Dornic (ed.), Attention and performance (pp.573-603). New York: Academic Press.

Schoonen, R., Hulstijn, J., \& Bossers, B. (1998). Metacognitive and language-specific knowledge in native and foreign language reading comprehension: An empirical study among Dutch students in grades 6, 8 and 10. Language Learning, 48,71106.

Singhal, M. (1998). A comparison of LI and L2 reading: Cultural differences and schema. The Internet TESL Journal, 4 (10).

Steffensen, M. S., Joag-Dev, C., \& Anderson, R.C. (1979). A cross-cultural perspective on reading comprehension. Reading Research Quarterly, XV, 1,10-29. 